\title{
Return to the new normal: Empirical analysis of changes in e- consumer behavior during the COVID-19 pandemic
}

\author{
František Pollák ${ }^{1, *}$, Peter Markovič ${ }^{2}$, Roman Vavrek ${ }^{3}$ and Michal Konečný ${ }^{1}$
}

1 Institute of Technology and Business in České Budějovice, Faculty of Corporate Strategy, Nemanická 436/7, 37010 České Budějovice, Czech Republic; michal.konecny@mail.vstecb.cz

2 Faculty of Business Management, University of Economics in Bratislava, Dolnozemská cesta 1/b, 85235 Bratislava, Slovakia; peter.markovic@euba.sk

3 Department of Public Economics, Faculty of Economics, VŠB-Technical University of Ostrava, Sokolská třída 33, 70200 Ostrava, Czech Republic; roman.vavrek@vsb.cz

* Corresponding author: frantisek.pollak@mail.vstecb.cz

\begin{abstract}
The global pandemic caused by the new coronavirus has largely changed established business practices. The aim of the study is to present the results of eighteen-month intensive research into the effects of the pandemic on e-consumer behavior. In one of the most active e-commerce markets in Europe, the Czech Republic, we analyzed a sample of more than one and a half million Facebook users in terms of their $\mathrm{C} 2 \mathrm{~B}$ interactions on the B2C activities of the five major e-commerce market players. The measurements were carried out in three periods, which corresponded to the onset of the first wave, peak, and fading of the second wave of the pandemic. This enabled us to monitor the effect of seasonality and the stabilization of patterns of consumer behavior during the coronavirus crisis. The results suggest that a specific panic pattern of e-consumer behavior was developed at the time of the onset of the pandemic. However, as the pandemic progressed, the market has adapted to a new normal, which, as evidenced by the change in trends, appears to be a combination of the pre-pandemic and pandemic behavioral patterns. Using a statistical analysis, it was possible to identify delta of changes within the patterns of consumer behavior, thus fulfilling the final condition for creating an empirical model of the COVID-19 pandemic impacts on e-consumer behavior presented in this study.
\end{abstract}

Keywords: e-commerce; m-commerce; innovation; business management; COVID-19; Czech Republic; Facebook

\section{Introduction}

The first decade of the twenty-first century was marked by accelerated digitization of processes within traditional business. Businesses gradually switched to online sales, even in areas that had only recently been the domain of the classic world of bricks and mortar stores [1-3]. The demand side of the market, represented mainly by final consumers, benefited from the opportunities provided by online technologies. The priority was to gain benefits in terms of lower prices of goods, the secondary motivation it was to satisfy higher demand [4]. However, the digital ecosystem was only an additional sales channel.

The first months of 2020, during which most market-oriented countries introduced forced closures, set a significant precedent for the continuity of e-market development [56]. In the effort to slow down the pandemic, traditional brick-and-mortar shops were closed almost overnight, making the online environment an affordable alternative for the safe procurement of demanded goods and services [7]. Information and communication technologies, but dominantly m-commerce tools, became interactive gateways to businesses [6].

In the Czech Republic, during the first days after the introduction of the state of emergency, sales in a significant part of the business sector decreased considerably, with 
companies using the $\mathrm{O} 2$ eKasa payment solution saw a drop of one-tenth of their normal turnover. In terms of growth, only the turnover of payments made by m-commerce instruments grew in the period under review, more precisely, there was a $20 \%$ increase compared to the average values [8]. Even the most important shops in the traditional world, such as petrol stations, saw significant revenue shortfalls, as they literally had to fight with the growing lack of drivers, despite the ever-decreasing oil prices [9]. As for traditional off-line players in the market, nearly a $100 \%$ drop in the volume of sales affected e.g. jewelry retailers, and catering and accommodation services saw a well above $90 \%$ drop in sales [10]. Buying behavior patterns began to change under the pressure of circumstances [11]. In a panic response to the situation, consumers began to focus on the accumulation of daily consumer goods, which was roughly the same regardless of the geographic location of the demand market [12]. In terms of the nature of the products, they differed only slightly. The dominant factor in deciding on the type and nature of products was mainly the economic situation of the buyer [13]. The market situation changed not only the patterns of consumer behavior, but also the overall perception of consumer life from the holistic perspective. Consumers began to consider the impact of their purchases, either on their health or on the environment as such [14]. Social distancing combined with working from home has accelerated these changes. From the point of view of the pace of change, we could see a significantly accelerated, even a revolutionary trend. Changes that would otherwise take years were implemented into the lives of individuals within a week in the conditions of forced global closure of shops due to the pandemic. At this point, we, as researchers, decided to build on our past projects $[4,15]$ and focus our research capacities on analyzing the impact of the COVID-19 pandemic on e-consumer behavior. In the initial phase, we implemented a series of pre-research qualitative data collection (visualized and described in more detail in the next chapter), which determines the basic methodological framework for the research. This phase was followed by the first measurement, or the first collection of empirical data.

As the pandemic progressed, its impact on consumer behavior took on new dimensions, and Euromoney Country Risk [16] conducted a global study to assess the risks of possible next waves to national economies, with the Czech Republic predicted risk beyond average of similar countries. At the same time, the risk profile of the Czech Republic deteriorated the most of all European countries. Together with the relatively vague prognosis of the pandemic, this has only multiplied a number of factors that needed to be taken into account in a comprehensive view of the situation. During this period, however, it was possible to see an indication of stabilizing trends. According to Nielsen retail audit [17], after the spring wave characterized also by panic buying, the situation stabilized in the summer. The stabilization had the form of a one-tenth decrease in shopper turnout, while online sales increased by more than $20 \%$ in the previous year. In a year-on-year comparison within the quarantine months, this was a $101 \%$ increase. The new summer normal of the online store represented a stabilization of the trend at $+50 \%$ compared to the previous year.

With the onset of the second wave, this increase increased to $+91 \%$. The trend of panic buying declined as consumers that learnt from the first wave realized that supply disruptions were highly unlikely [18-19]. These facts were also reflected in the e-consumer behavior of the examined sample during the second measurement, in which both the regional specificity parameter and the seasonality parameter were tested.

With the aftermath of the second wave of the pandemic in the first half of 2021, it was possible to proceed with the research of the context, as the empirical material collected during the two measurements showed a high degree of specificity. In order to confirm the assumptions, the third and final collection of empirical material was carried out (described in more detail and visualized in the following chapter). Within the study of the current state and the continuous deepening of knowledge in the issue, several assumptions made in the previous phases of the research were confirmed. This was mainly the assumption of stabilized consumer online habits [20-21], preference for online shopping over traditional way of shopping [22-24], preference for working from home [25], or the 
digitization of the offer of hitherto dominant off-line products [26-28]. In general, we can see the stabilization on both the supply and demand. Both sides of the market have been able to adapt to the new situation [29-30]. Regarding experts' view of trends across the global market, the TOP 10 Global Consumer Trends study [31] presents a comprehensive and integrated study particularly pointing out the emergence of a trend towards sustainability, desire for comfort, or digital reality and time flexibility. The last of these trends is important from the perspective of the study being submitted.

Based on the results of our own research [32-33], in the first phase of our research, patterns of consumer behavior were identified that showed panic behavior; given the situation, it was a relatively logical and predictable fact. Under the pressure of circumstances, consumers maximized their consumption by seeking additional benefits through online consumer-to-business (C2B) activities. Both sides of the market found space for the interaction in the virtual environment, where social networks, in our case especially the social network Facebook, replaced the traditional meeting space in the times of social distancing [34-36]. As is well known from reference research [37-38], in the environment of Facebook, business entities carrying out their e-marketing activities of a business-to-consumer (B2C) nature [37-38]. They regularly communicate their e-marketing messages to target markets represented by fans of their profiles [39]. It was these interactions and their metadata that provided the empirical material for statistical processing.

Despite the high specificity of seasonality or regional specificity, the trends stabilized at the turn of 2020/2021 [40].

At this point, we come to the definition of a basic scientific problem that needs to be clarified before an empirical model of the effects of a pandemic on e-consumer behavior can be finalized. Specifically, it is a definition of the degree of change in behavior across the various stages of the pandemic. The research problem is converted into a research question as follows:

How has the COVID-19 pandemic affected e-consumer behavior in the monitored market?

To solve the research problem, the market is represented by both the supply and demand side. The demand side consists of consumers / users of the social network Facebook. The supply side consists of the main representatives of the Czech e-commerce market, represented by their profiles in the form of fan pages.

From the point of view of the structure of the study, the following chapters will build on the introduction, which synthesizes and presents the reference resources in the chronological order. The theoretical framework was complemented by the results of our research $[4,15,32-33,40]$. The aim of the synthesis was to define a research problem and formulate research questions. Based on this framework, we will further describe the methodology, which will be complemented by the visualization of individual research phases. The research results are presented and discussed in the next chapter. Finally, an empirical model is completed, visualized and described as a final output of eighteen-month efforts of the authors to find an answer to the research question. In the conclusion, the results of the research are evaluated and the basic implications for science and practice are specified.

The presented study is the final output of a comprehensive study of COVID-19 pandemic impacts on e-consumer behavior.

\section{Materials and Methods}

The main goal of the study is to identify changes in the interactions of digital customer communities of selected representatives of electronic business on the Czech market during 3 observation periods made in the COVID 19 pandemic. The research question was formulated as follows:

How has the covid pandemic affected e-commerce behavior in the Czech Republic?

This research question is assessed from two points of view. The first one is represented by consumer activities, namely the number of posts, likes and shares. The second one analyses the trend and differences in corporate activities by means of the number of posts. 
From the point of view of the research genesis (presented in the scheme below), the study is the output of Phase 5 of the research.

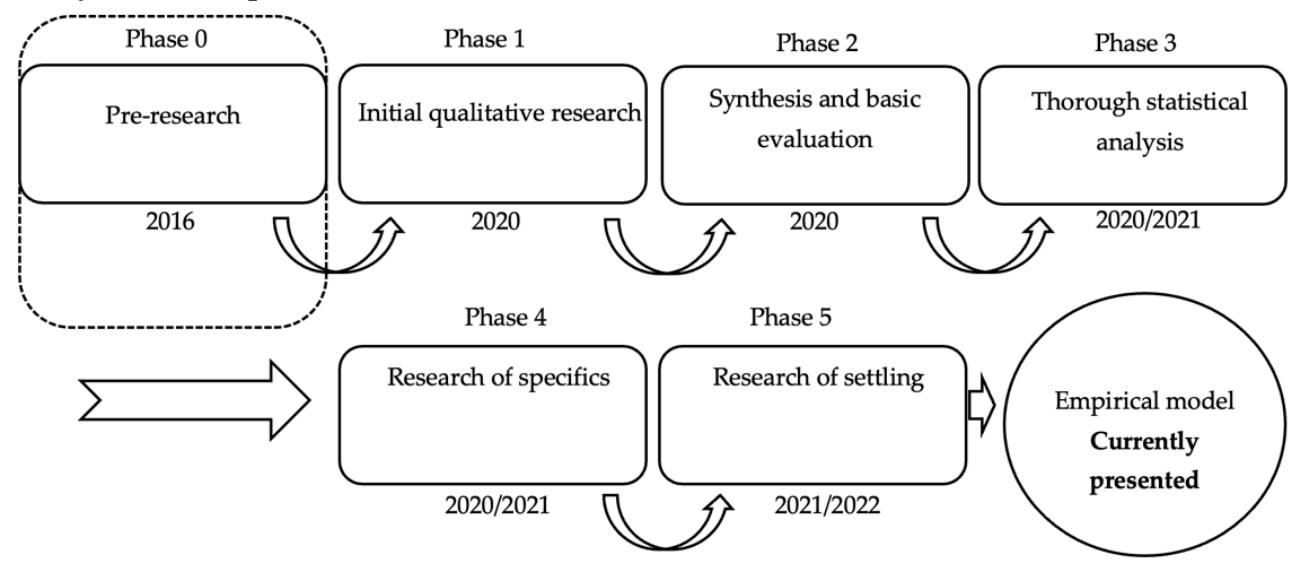

Figure 1. Research phases.

The empirical material necessary to create the model was collected through three measurements carried out in the following periods:

a) $1^{\text {st }}$ observation: from 12 March 2020 to 17 May 2020,

b) $2^{\text {nd }}$ observation: from 27 November 2020 to 14 January 2020,

c) $3^{\text {rd }}$ observation: from 12 March 2021 to 17 May 2021.

The research was conducted by means of monitoring Facebook activity on the official profiles/ fan pages of the 5 largest Czech e-shops, ranked based on the order published by the online journal Ecommerce Bridge [41], specifically profiles of Alza, Mall, CZC, Aukro and Lidl Czech Republic. The research sample thus consists of more than 1,5 mil. users with the following structure (see Table 1):

Table 1. Structure of the research sample

\begin{tabular}{lr}
\hline \multicolumn{1}{c}{ Facebook profile } & users/fans \\
\hline Alza.cz & 264,865 \\
Mall.cz & 207,747 \\
CZC.cz & 232,694 \\
Aukro.cz & 110,201 \\
Lidl Czech Republic & 778,673 \\
Total & $1,594,180$ \\
\hline
\end{tabular}

Data were collected daily for thirteen months by the interested researchers, who recorded the number, type and nature of user interactions, as well as the number and nature of contributions /posts/ published on the profiles of selected e-commerce entities.

The interactions of customer groups (for the purposes of the analysis) represent the reactions of individuals to e-marketing communication /posts/, which the subject / profile manager of the e-commerce entity published during the monitored period on the official profile of the given company.

The reactions /in our case referred to as user interactions/ had the forms of comments, likes and sharing. The analysis is processed in several stages, or parts, using the following mathematical-statistical methods including:

Shapiro-Wilk test

$$
S W=\frac{\left(\sum u_{i} x_{i}\right)^{2}}{\sum u_{i}^{2} \sum\left(x_{i}-\bar{x}\right)^{2}}
$$

where: $u_{i}-$ constant

$X_{i}-$ value of $i$-th statistical unit 


$$
\bar{x} \text { - average value }
$$

Kruskal-Wallis test

$$
Q=\frac{12}{n(n-1)} \sum_{i=1}^{I} \frac{T_{i}^{2}}{n_{i}}-3(n+1)
$$

where: $\quad n-$ number of observation periods

$\mathrm{n}_{\mathrm{i}}$ - number of observation periods in the i-th group

$T_{i}^{2}$ - total sum of ranks in the i-th group

Mann-Whitney test

$$
U^{\prime}=n_{y} n_{x} \frac{n_{y}\left(n_{y}+1\right)}{2}-R_{y} ; U=n_{y} n_{x}-U^{\prime}
$$

where: $\quad n_{x}$ - number of observation periods, or the extent of the $x$-th sample $\mathrm{n}_{\mathrm{y}}$ - number of observation periods, or the extent of the $\mathrm{x}$-th sample Ry - sum of the order of the $y$-th file

$\mathrm{U}, \mathrm{U}^{\prime}$ - test statistics

Levene test

$L E=\frac{(N-k)}{(k-1)} \frac{\sum_{i=1}^{k} N_{i}\left(Z_{i}-Z_{. .}\right)^{2}}{\sum_{i=1}^{k} \sum_{j=1}^{N_{i}}\left(Z_{i j}-Z_{i .}\right)^{2}}$

where: $\quad \mathrm{k}$-number of values in the monitored variable category

$\mathrm{N}$ - total number of observation periods

$\mathrm{N}_{\mathrm{i}}$ - number of observation periods in the i-th group

$\mathrm{Y}_{\mathrm{ij}}$ - measured value of the $\mathrm{j}$-th unit of the $\mathrm{i}$-th group

$\overline{Y_{l}}$ - average value of the i-th group

$\tilde{Y}_{i} \quad$ - median of the i-th group

$Z_{\text {.. }}$ - average of the groups $Z_{\mathrm{ij}}$

$Z_{i}$. - average of $Z_{i j}$ for the $i$-th group

Kolmogorov-Smirnov test

$$
\begin{aligned}
D_{n_{1}, n_{2}}= & \sup \left|F_{1, n_{1}}(x)-F_{2, n_{2}}(x)\right| \\
& -\infty<x<\infty
\end{aligned}
$$

where: $\quad F_{1, n_{1}}(x)$ - empirical distribution function of the first sample

$F_{2, n_{2}}(x)$ - empirical distribution function of the second sample

Simple regression analysis using OLS method verified by the coefficient of determination

$$
R^{2}=\frac{\sum_{i=1}^{n}\left(y_{i}-\hat{y}_{i}\right)^{2}}{\sum_{i=1}^{n}\left(y_{i}-\bar{y}_{i}\right)^{2}}
$$

where: $\quad y_{i}$ - measured value of the dependent variable

$\hat{y}_{i}$ - estimated value of the dependent variable

$\bar{y}_{i}$ - average value of the dependent variable

The above mathematical-statistical methods are used for the verification of partial results of the research. The main output of the research is a complex parameter identified as engagement ratio, the parameter is calculated as follows:

$$
E R=\frac{\tilde{L}_{\text {norm }}+\tilde{C}_{\text {norm }}+\tilde{S}_{\text {norm }}}{\tilde{P}_{\text {norm }}}
$$

where: $\quad \tilde{L}_{\text {norm }}$ - standardized mean value (median) of the number of likes within one observation 
$\tilde{C}_{\text {norm }}$ - standardized mean value (median) of the number of comments within one observation

$\tilde{S}_{\text {norm }}$ - standardized mean value (median) of the number of shares within one observation

$\tilde{P}_{\text {norm }}$ - standardized mean value (median) of the number of posts within one observation

Due to the different range of variables, outliers or the absence of a normal distribution, margin normalization is used for the engagement ratio (ER):

$$
y_{i j}=\frac{x_{i j}-\min \left(x_{j}\right)}{\max \left(x_{j}\right)-\min \left(x_{j}\right)}
$$

Implemented analysis and statistical evaluation is processed in MS Excel, Statistica 13.4 and Statgraphics XVIII.

\section{Results and Discussion}

The processed analysis is performed at the level of individual e-commerce parameters. The processing consists of a) a comparison using selected moment characteristics and the related tests, $b$ ) trend comparison using OLS regression model. Both analyses are performed separately for weekends and working days. The purpose of such double processing is to point out the absolute differences of the level of e-commerce parameters between the observation periods and, consequently, their development over time.

\subsection{Evaluation of trends and changes in the number of posts}

The development of the number of posts over time across the 3 observation periods is shown in Figure 2. Based on this graphical comparison, it is possible to consider the trend during the working days in the first and third observation as similar, or identical. Higher variability is reported in the second observation, but this is again attributed to the Christmas holidays. The trend during the weekend is continual with a slight decrease in the number of posts in absolute terms.
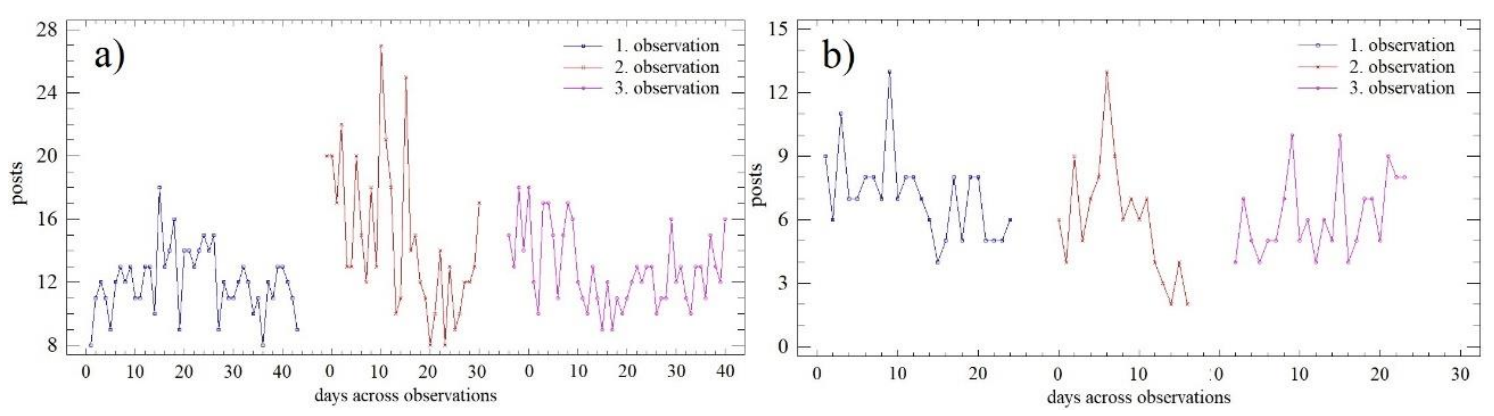

Figure 2. Scatter plot of number of posts across observation periods. (a) working days; (b) weekend

The above trends are quantified by the OLS regression model described in Table 2 . In the case of the number of posts, very similar trends can be observed over the working days and weekends. Between the first and second observation, there is a decrease in the daily increment while the predictive value of each model increases.

Table 2. Linear regression model for posts during working days and weekends over each observation.

\begin{tabular}{ll}
\hline & \multicolumn{1}{c}{ Regression models } \\
\hline \multirow{2}{*}{ working days } & O1: posts $=\exp \left(0.802651^{*} \ln (\right.$ days $\left.)\right)\left(\mathrm{R}^{2}=91.58\right)$ \\
& O2: posts $=\exp \left(0.646466^{*} \ln (\right.$ days $\left.)\right)\left(\mathrm{R}^{2}=99.79\right)$ \\
& O3: posts $=\exp \left(0.55297^{*} \ln (\right.$ days $\left.)\right)\left(\mathrm{R}^{2}=99.27\right)$ \\
\hline
\end{tabular}




$$
\begin{array}{ll}
\text { O1: posts }=\exp \left(0.732627^{*} \ln (\text { days })\right)\left(R^{2}=83.24\right) \\
\text { weekends } & \text { O2: posts }=\exp \left(0.476767^{*} \ln (\text { days })\right)\left(R^{2}=90.30\right) \\
\text { O3: posts }=\exp \left(0.450476^{*} \ln (\text { days })\right)\left(R^{2}=97.73\right)
\end{array}
$$

The differences in the two monitored parameters were confirmed as statistically significant for the number of posts during the working days $(\mathrm{LE}=16.405 ; \mathrm{p}<0.01 ; \mathrm{Q}=6.064$; $\mathrm{p}<0.05$ ); within 3 observation periods, there was a change in the mean value as well as the variance. The opposite trend is observed at weekends, which is in line with both the Levene test $(\mathrm{LE}=1.167 ; \mathrm{p}=0.318)$ and the Kruskal-Wallis test $(\mathrm{Q}=3.739 ; \mathrm{p}=0.154)$. Figure 3 shows the significant difference in distribution functions during the individual observation periods. Differences were confirmed in all cases when comparing the mean values $\left(\mathrm{W}_{\mathrm{obs} 1}=979 ; \mathrm{p}<0.01 ; \mathrm{W}_{\mathrm{obs} 2}=523.5 ; \mathrm{p}<0.01 ; \mathrm{W}_{\mathrm{obs} 3}=980 ; \mathrm{p}<0.01 ;\right)$ as well as the distribution functions themselves $\left(\mathrm{K}-\mathrm{S}_{\mathrm{obs} 1}=0.875 ; \mathrm{p}<0.01 ; \mathrm{K}-\mathrm{S}_{\mathrm{obs} 2}=0.878 ; \mathrm{p}<0.01 ; \mathrm{K}-\mathrm{S}_{\mathrm{obs} 3}=0.955\right.$; $\mathrm{p}<0.01)$.
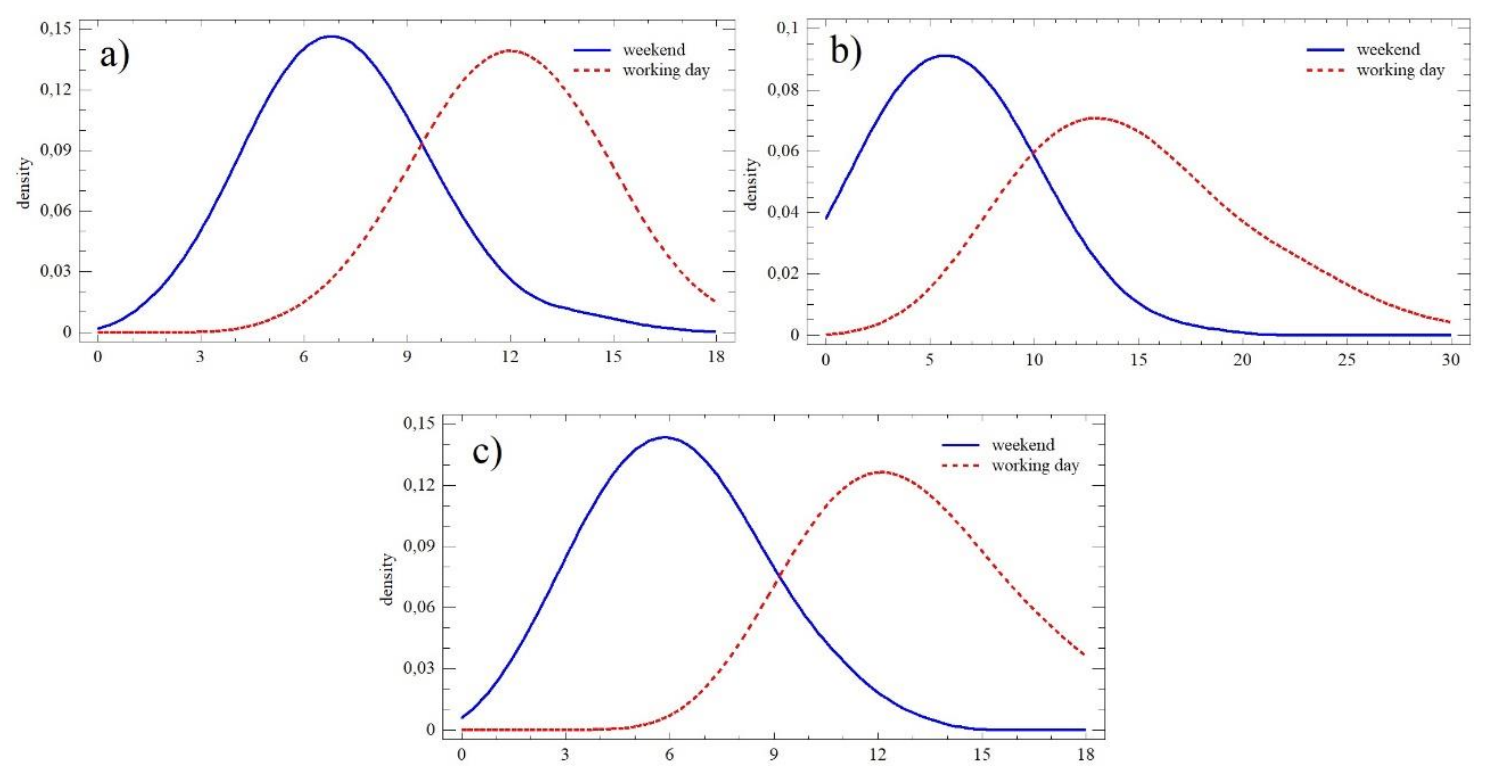

Figure 3. Density plot of number of posts over 3 monitored observation periods. (a) observation no. 1 ; (b) observation no. 2; (c) observation no. 3.

\subsection{Evaluation of trends and changes in the number of comments}

The development of the number of comments over time within the 3 observation periods is shown in Figure 4. During the working days, the trend can be described as declining, with smaller absolute differences in the individual monitored days. At weekends, the homogeneity across the individual observation periods is higher, which negates the Christmas period recorded within the second observation. The differences in the number of comments during the individual days persist, but smaller in absolute terms.
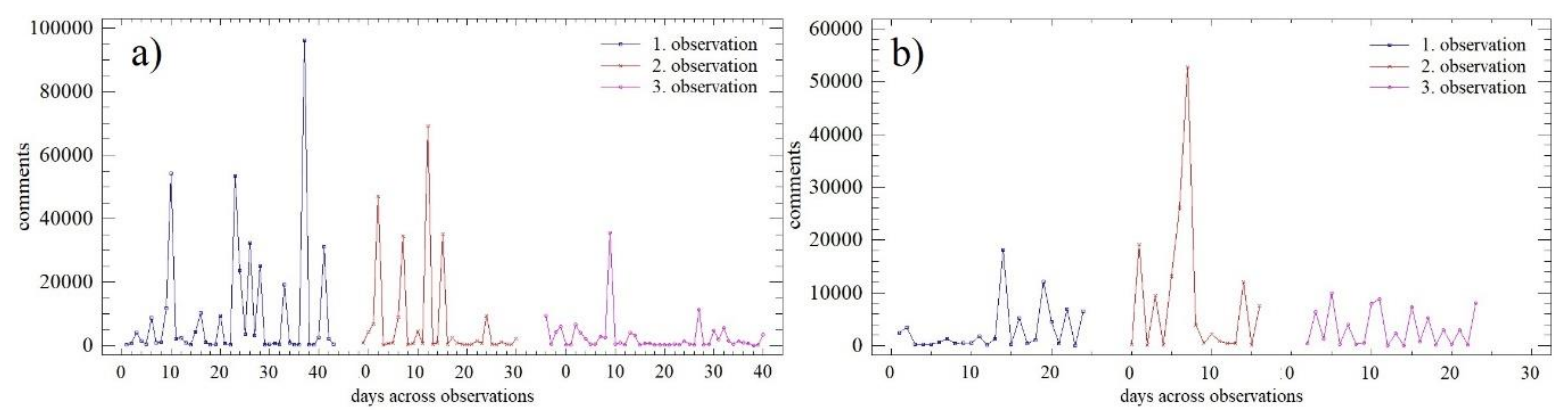
Figure 4. Scatter plot of number of comments across observation periods. (a) working days; (b) weekend

The above trends can be quantified using the OLS regression model, which is described in Table 3. The number of comments shows almost the same development during the working days and weekends. There is a decrease in daily increment, while at the same time the predictive value of individual models increases.

Table 3. Linear regression model for comments during working days and weekends in each observation.

\begin{tabular}{cc}
\hline & Regression models \\
\hline \multirow{2}{*}{ working days } & O1: comments $=\exp \left(2.44449^{*} \ln (\right.$ days $\left.)\right)\left(\mathrm{R}^{2}=87.23\right)$ \\
& O3: comments $=\exp \left(1.48921^{*} \ln (\right.$ days $\left.)\right)\left(\mathrm{R}^{2}=95.62\right)$ \\
\hline \multirow{2}{*}{ weekends } & O1: comments $=\exp \left(2.70824^{*} \ln (\right.$ days $\left.)\right)\left(\mathrm{R}^{2}=85.79\right)$ \\
& O3: comments $=\exp \left(2.17092^{*} \ln (\right.$ days $\left.)\right)\left(\mathrm{R}^{2}=93.07\right)$ \\
& \\
&
\end{tabular}

During the working days, statistically significant differences in the mean value (median) were not confirmed $(\mathrm{Q}=1.331 ; \mathrm{p}=0.513)$. However, differences in variance were confirmed $(\mathrm{LE}=8.664 ; \mathrm{p}<0,01)$, which reflects the above-mentioned reduction in differences in daily values over time. Similar conclusions can be made for weekends ( $\mathrm{LE}=8.147$; $\mathrm{p}<0.01 ; \mathrm{Q}=2.532 ; \mathrm{p}=0.281$ ). A comparison of the weekend and the working days within all three observation periods is presented in Figure 5. The distribution functions shown in each of the observation periods can be described as identical (K-Sobs1 $=0.768 ; \mathrm{p}=0.596$; K$\left.S_{\text {obs2 }}=0.759 ; \mathrm{p}=0.611 ; \mathrm{K}-\mathrm{S}_{\mathrm{obs} 3}=0.726 ; \mathrm{p}=0.667\right)$. The conformity can also be determined using the Mann-Whitney test and a comparison of the mean value.
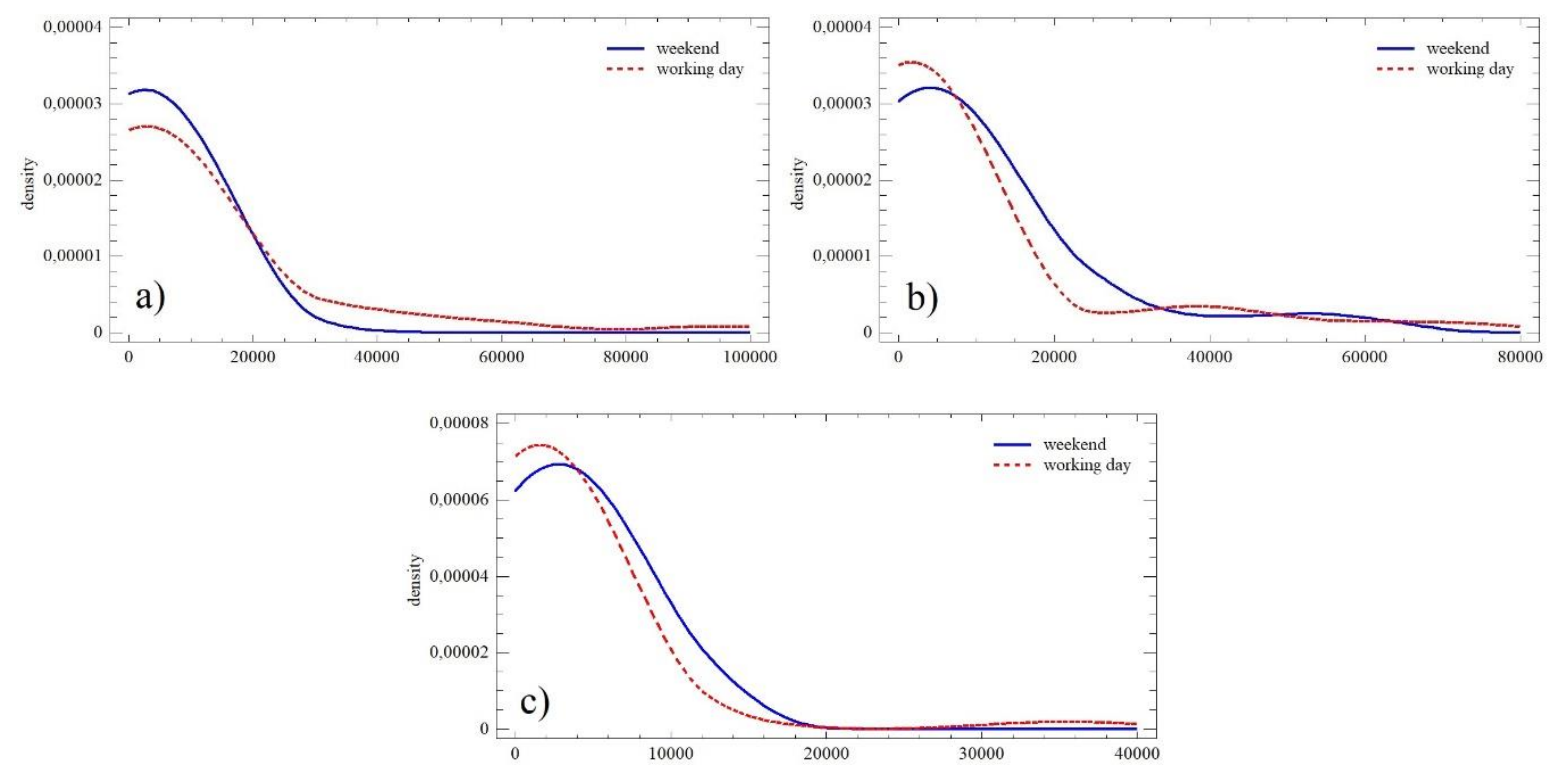

Figure 5. Density plot of number of comments over 3 monitored observation periods. (a) observation no. 1; (b) observation no. 2; (c) observation no. 3.

\subsection{Evaluation of trends and changes in the number of likes}

Figure 6 shows the development of the number of likes over time within all 3 observation periods. During the working days, the trend is similar, with absolute differences in the individual monitored days that diminish over time. At weekends, the homogeneity in the first and the second observation periods is higher, which negates the Easter, or the 
Christmas period recorded in these observation periods. The differences in the number of likes during the individual days persist, but smaller in absolute terms (especially in the third observation).
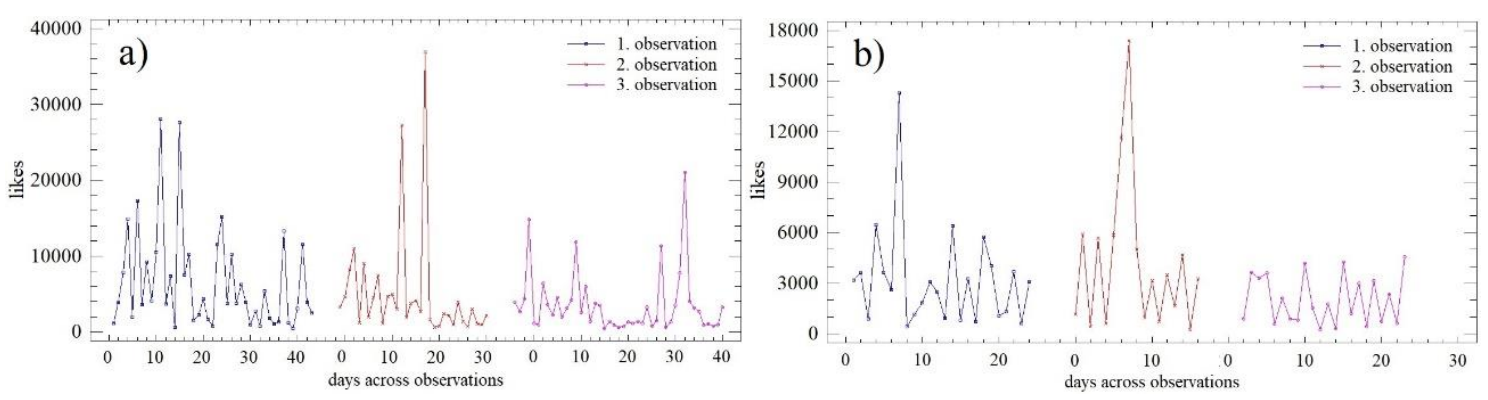

Figure 6. Scatter plot of number of likes in observation periods. (a) working days; (b) weekend

For the quantification the above-illustrated trends, the OLS regression model is used, which is presented in Table 4 . In the case of the number of likes, we can see a very similar development during the working days and weekends. There is a continuous decrease in daily increment, while the predictive value of individual models increases (especially between the first and the second observation).

Table 4. Linear regression model for likes during working days and weekends in each observation.

\begin{tabular}{cl}
\hline & \multicolumn{1}{c}{ Regression models } \\
\hline Working days & O1: likes $=\exp \left(2.64873^{*} \ln (\right.$ days $\left.)\right)\left(\mathrm{R}^{2}=88.57\right)$ \\
& O3: likes $=\exp \left(1.68417^{*} \ln (\right.$ days $\left.)\right)\left(\mathrm{R}^{2}=98.37\right)$ \\
\hline weekends & O1: likes $=\exp \left(2.96765^{*} \ln (\right.$ days $\left.)\right)\left(\mathrm{R}^{2}=86.33\right)$ \\
& O2: likes $=\exp \left(2.2266^{*} \ln (\right.$ days $\left.)\right)\left(\mathrm{R}^{2}=97.50\right)$ \\
& O3: likes $=\exp \left(1.183614^{*} \ln (\right.$ days $\left.)\right)\left(\mathrm{R}^{2}=98.37\right)$ \\
\hline
\end{tabular}

During the working days, statistically significant differences in the mean value (median) were confirmed $(\mathrm{Q}=6.105 ; \mathrm{p}<0.05)$ and the variance were confirmed $(\mathrm{LE}=3.226$; $\mathrm{p}<0.05)$, which are affected by the above-mentioned holidays. During weekend, homoscedasticity is observed ( $\mathrm{LE}=3.585 ; \mathrm{p}<0.05)$, but the difference at the level of mean value is confirmed again. $(Q=3.213 ; \mathrm{p}=0.200)$. A comparison of weekends and working days in all three observation periods is presented in Figure 7. Except for the first observation, the distribution functions can be described as identical $\left(\mathrm{K}-\mathrm{S}_{\mathrm{obs} 1}=0.349 ; \mathrm{p}<0.05 ; \mathrm{K}-\mathrm{S}_{\mathrm{obs} 2}=\right.$ $0.176 ; \mathrm{p}=0.879 ; \mathrm{K}-\mathrm{S}_{\mathrm{obs} 3}=0.231 ; \mathrm{p}=0.413$ ). The conformity cannot be confirmed using the Mann-Whitney test, i.e., there are significant differences between the first and second observation periods $\left(\mathrm{W}_{\mathrm{obs} 1}=684 ; \mathrm{p}<0.05 ; \mathrm{W}_{\mathrm{obs} 2}=277 ; \mathrm{p}<0.05 ; \mathrm{W}_{\mathrm{obs} 3}=610 ; \mathrm{p}=0.126\right)$. 

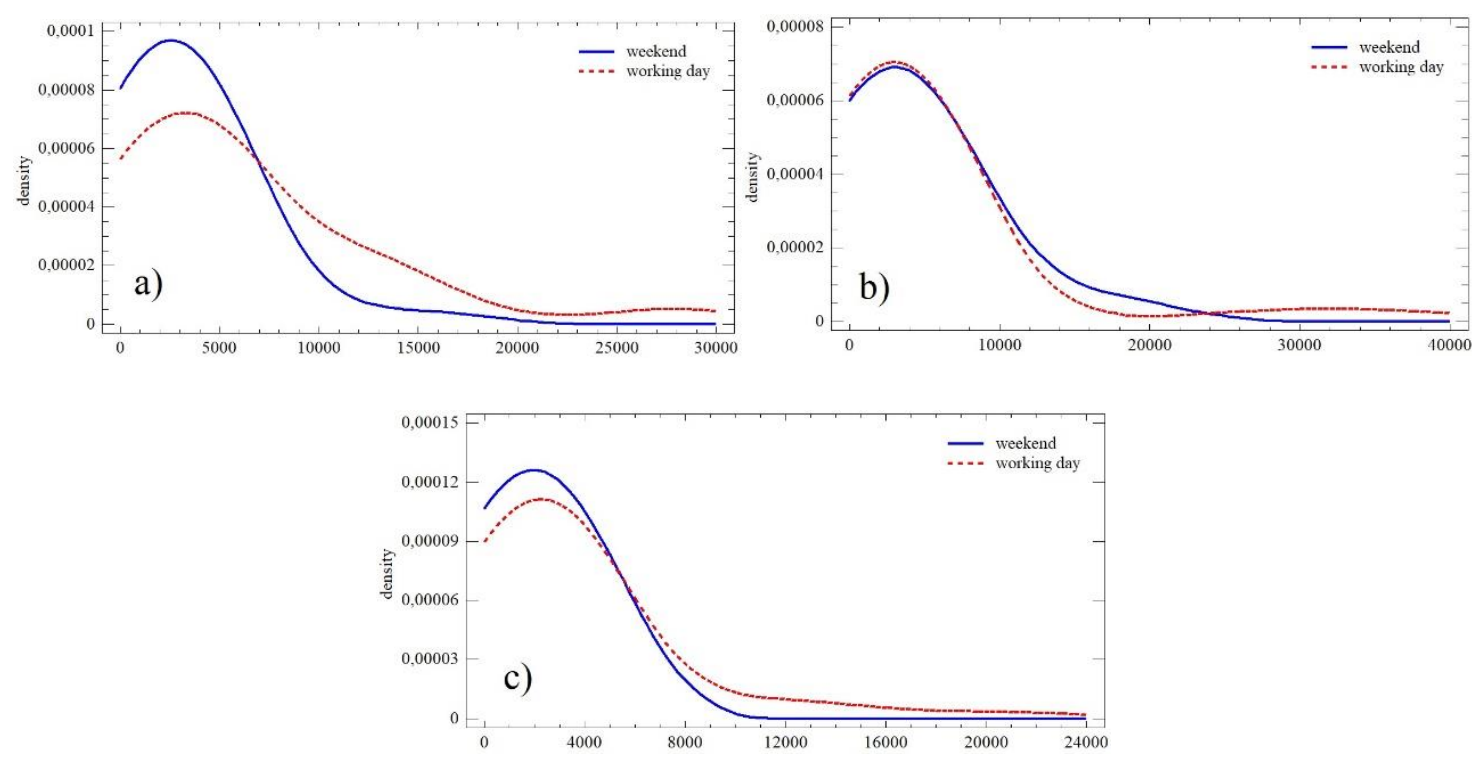

Figure 7. Density plot of number of likes over 3 monitored observation periods. (a) observation no. 1 ; (b) observation no. 2; (c) observation no. 3 .

\subsection{Evaluation of trends and changes in the number of shares}

The development of the number of shares over time within the 3 observation periods is shown in Figure 8. Based on this graphical comparison, it is possible to describe the trend during working days in the first and third observation as similar or identical. Higher variability is reported in the second observation, but this is again attributed to the Christmas holidays. The trend during the weekend is continual with a slight decrease in the number of shares in absolute terms.
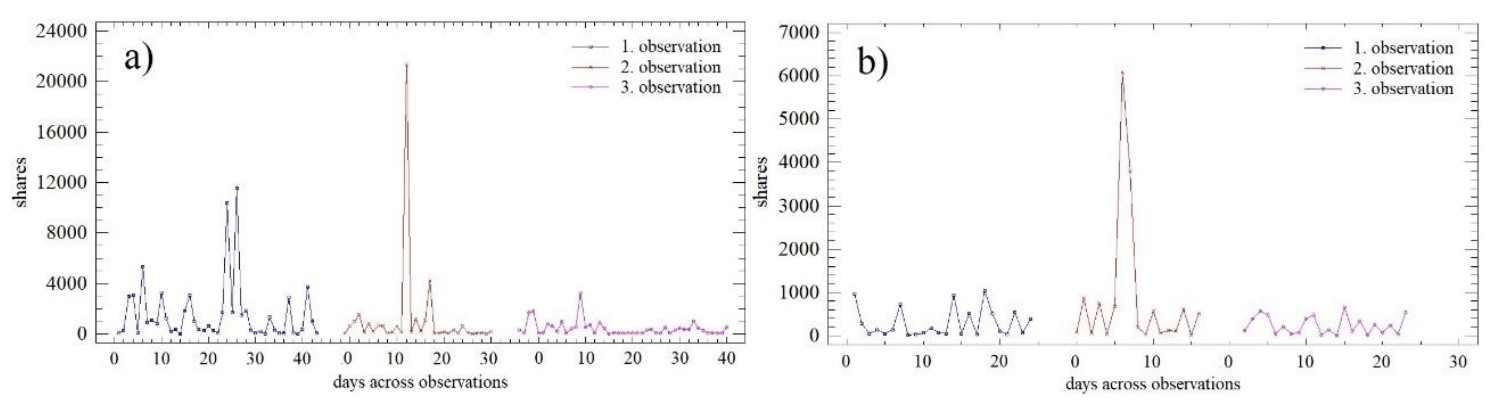

Figure 8. Scatter plot of number of shares in observation periods. (a) working days; (b) weekend

The OLS regression model is used to quantify the above trends (see Table 5). In the case of the number of shares, a very similar development is seen during working days and weekends. There is a decrease in daily increment especially between the first and the second observation, while the predictive value of individual models slightly increases.

Table 5. Linear regression model for shares during working days and weekends in each observation. Regression models

\begin{tabular}{ll}
\hline & \multicolumn{1}{c}{ Regression models } \\
\hline \multirow{2}{*}{ working days } & O2: shares $=\exp \left(1.97912^{*} \ln (\right.$ days $\left.)\right)\left(\mathrm{R}^{2}=83.26\right)$ \\
& O3: shares $=\exp \left(1.33026^{*} \ln (\right.$ days $\left.)\right)\left(\mathrm{R}^{2}=91.65\right)$ \\
& O1: shares $=\exp \left(1.88783^{*} \ln (\right.$ days $\left.)\right)\left(\mathrm{R}^{2}=81.68\right)$ \\
\hline \multirow{2}{*}{ weekends } & O2: shares $=\exp \left(1.54268^{*} \ln (\right.$ days $\left.)\right)\left(\mathrm{R}^{2}=90.11\right)$ \\
\hline
\end{tabular}


O3: shares $=\exp \left(1.21997^{*} \ln (\right.$ days $\left.)\right)\left(\mathrm{R}^{2}=92.49\right)$

The differences in the two monitored parameters were confirmed as statistically significant for the number of shares during working days $(\mathrm{LE}=4.097 ; \mathrm{p}<0.05 ; \mathrm{Q}=7.848 ; \mathrm{p}<$ $0.05)$, i.e. in the 3 observation periods, there was a change in the mean value as well as the variance. A partially opposite situation is recorded at weekends, when we find conformity at the level of the mean vale $(\mathrm{Q}=1.302 ; \mathrm{p}=0.521)$. The difference in the variance is confirmed $(\mathrm{LE}=7.551 ; \mathrm{p}<0.01)$. Figure 9 shows the similarity in distribution functions during the individual observation periods $\left(\mathrm{K}-\mathrm{S}_{\mathrm{obs} 1}=0.395 ; \mathrm{p}<0.05 ; \mathrm{K}-\mathrm{S}_{\text {obs2 }}=0.141 ; \mathrm{p}=0.979 ; \mathrm{K}\right.$ $\mathrm{S}_{\mathrm{obs} 3}=0.177 ; \mathrm{p}=0.738$ ). Differences at the level of mean value were confirmed only in the first observation in all cases when comparing the mean values $\left(\mathrm{W}_{\mathrm{obs} 1}=740.5 ; \mathrm{p}<0.01 ; \mathrm{W}_{\mathrm{obs} 2}\right.$ $=279 ; \mathrm{p}=0.891 ; \mathrm{W}_{\mathrm{obs} 3}=556 ; \mathrm{p}=0.419$ ).
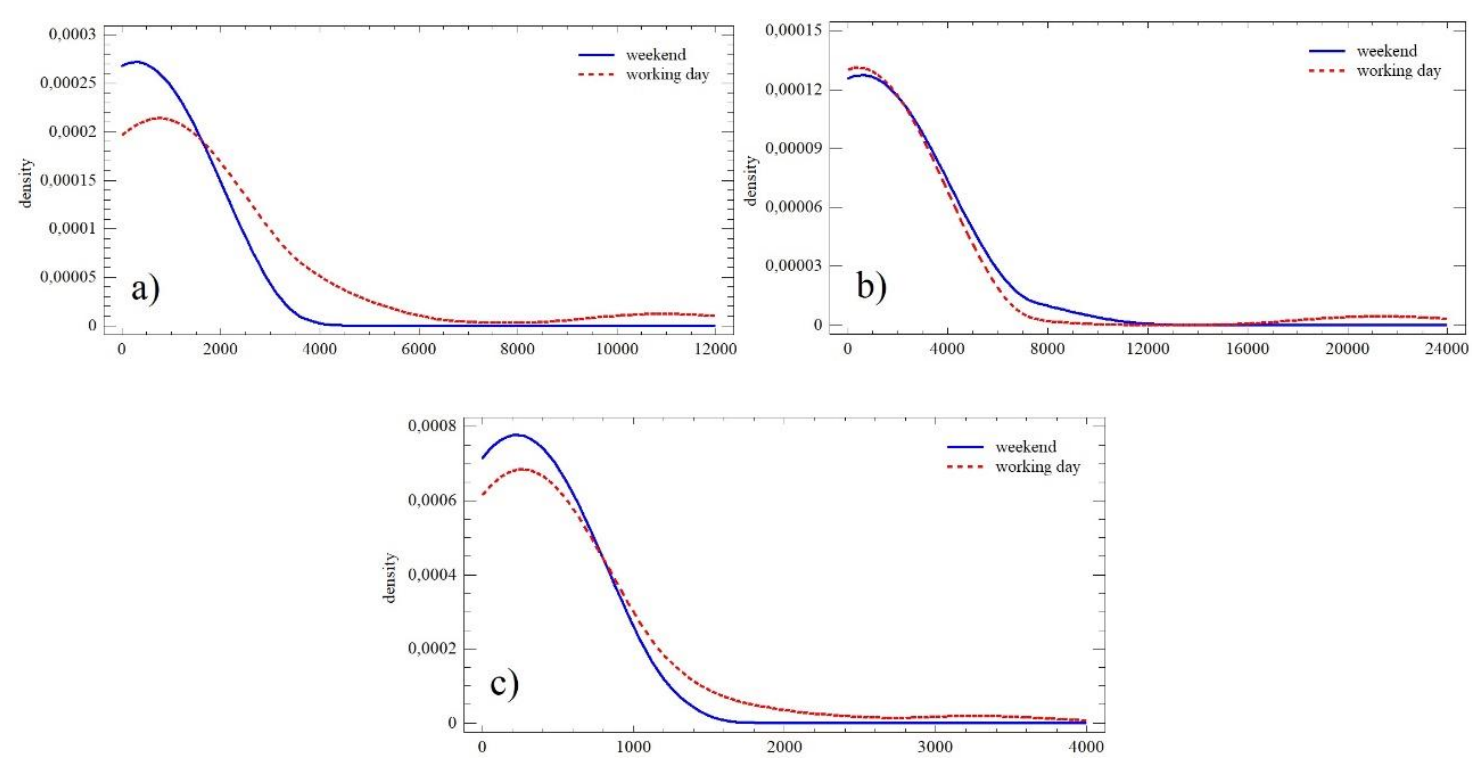

Figure 9. Density plot of number of shares in 3 observation periods. (a) observation no. 1; (b) observation no. 2; (c) observation no. 3.

\subsection{Delta of changes- Engagement ratio over observation periods}

The results of the above analysis performed at the level of individual e-commerce parameters are highly heterogeneous. The only phenomenon that occurs when monitoring the number of posts, comments, likes and shares is a significant decrease in the trend level (regressor) of the regression model, see Table 6:

Table 6. Comparison of the trend level (regressor) of the regression model.

\begin{tabular}{lll}
\hline & working days & weekends \\
\hline posts & $\downarrow 30.11 \%$ & $\downarrow 38.51 \%$ \\
comments & $\downarrow 39.07 \%$ & $\downarrow 34.82 \%$ \\
likes & $\downarrow 36.41 \%$ & $\downarrow 60.11 \%$ \\
shares & $\downarrow 42.59 \%$ & $\downarrow 35.37 \%$ \\
\hline
\end{tabular}

From the point of view of the absolute change of the mean value (Table 7), the monitored e-commerce parameters can be divided into two groups. The first group includes comments and shares whose trend during weekends and working days is the same (the decrease during working days is accompanied by a decrease during weekends). The second group consists of posts and likes, where a decline or stagnation is noticed regardless of the above division.

Table 7. Comparison of the absolute changes of the mean value (median). 


\begin{tabular}{lll}
\hline & working days & weekends \\
\hline posts & $0 \%$ & $\downarrow 21.42 \%$ \\
comments & $\downarrow 47.55 \%$ & $\uparrow 113.99 \%$ \\
likes & $\downarrow 32.48 \%$ & $\downarrow 41,17 \%$ \\
shares & $\downarrow 51.57 \%$ & $\uparrow 45.18 \%$ \\
\hline
\end{tabular}

The effectiveness of activities (posts) of the monitored institutions, considering the reactions in the forms of likes, comments and shares, is shown using engagement ratio in Figure 10. The trend monitored within the 3 observation periods is significantly different for weekends and working days. During the working days, after a significant decline in the $2^{\text {nd }}$ observation, the recovery in the $3^{\text {rd }}$ observation with greater customer activity in the form of shares is noticed. In the context of the change in the number of posts, the engagement ratio doubles as well. During weekends, in the 3rd observation, the interest of customers grows significantly, which is reflected in the significant growth of the engagement ratio.

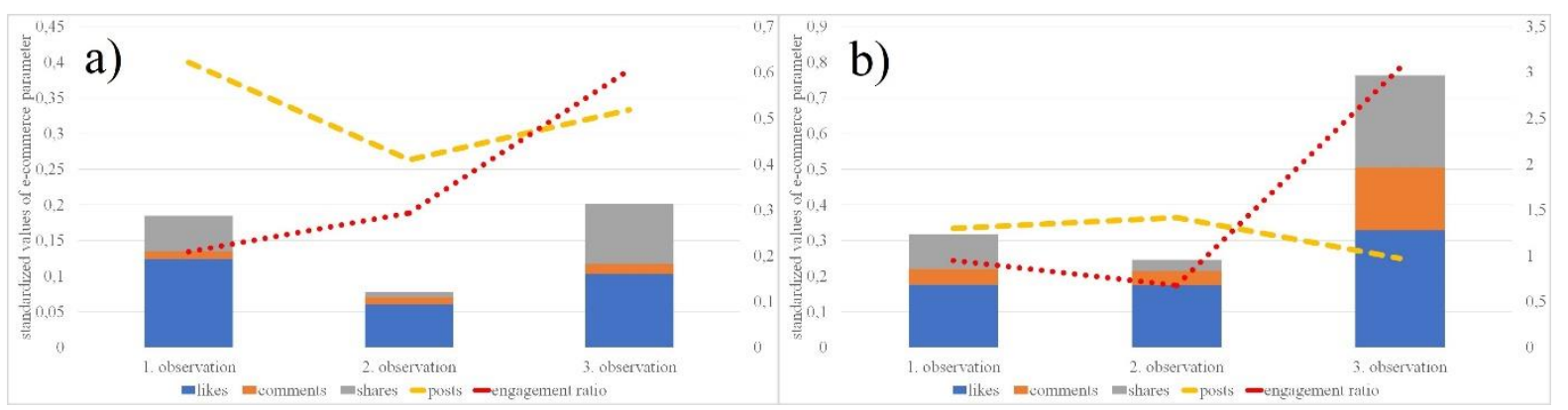

Figure 10. Engagement ratio and its components over individual observation periods. (a) working days; (b) weekend.

Based on the presented findings, the research task can be considered solved. The individual partial analyses described in chapters 4.1-4.4 provided the answer to the research question. Considering the comparison of trend levels, significant changes were noticed in e-consumer behavior in all three observation periods, specifically the decline in panic reactions recorded in the first observation and subsequent stabilization of parameters in the form of a new normal. From the point of view of the effectiveness and management of emarketing communication of e-commerce entities, there is an increase in efficiency represented by the engagement ratio parameter, where the response of target markets per unit of activity (post) slightly increases during working days. The return to the pre-crisis normal can be observed especially during weekends, where the values of user activity increased significantly observation periods. Users are thus partially returning to their precrisis weekend patterns of e-consumer behavior. A new normal is created by the synthesis of old and new patterns, as seen in Figure 11. 


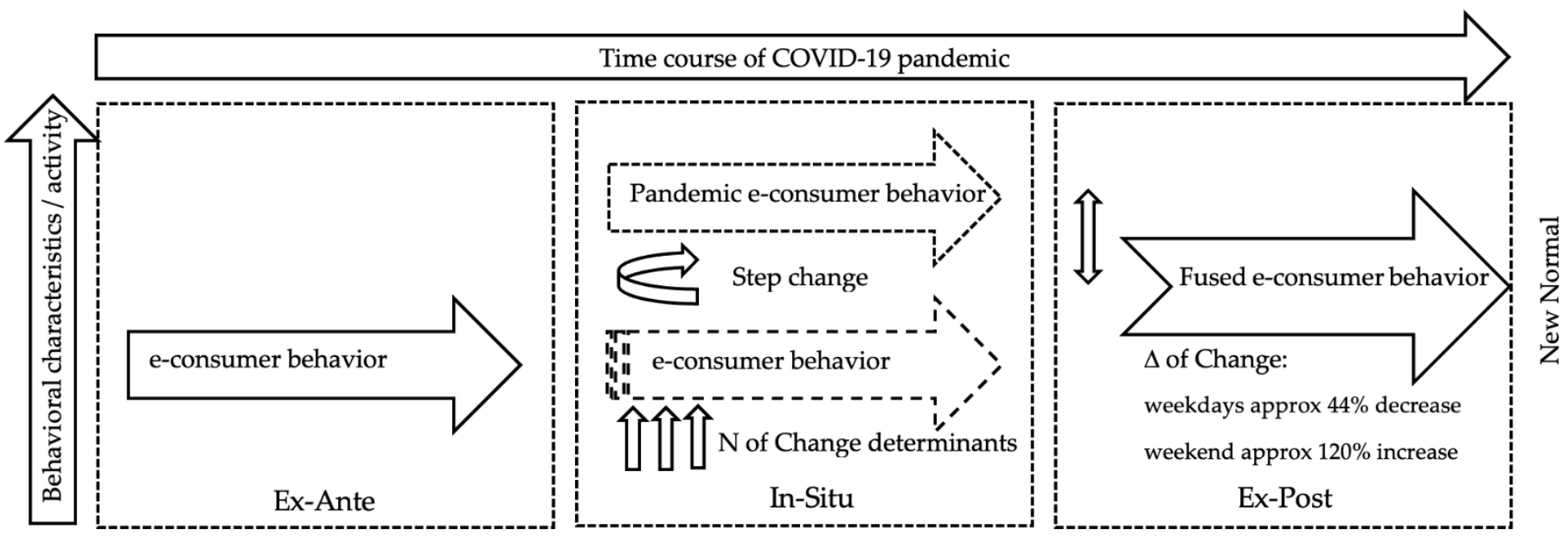

Figure 11. Empirical model of the impact of the COVID-19 pandemic on e-consumer behavior

By answering the research question, it is possible to move smoothly to the conclusion of knowledge obtained on the basis of the research.

\section{Conclusions}

E-commerce underwent a significant stress test at the time of the onset of the global COVID-19 pandemic. Panic buying, partial closure of the brick-and-mortar shops and the overall market uncertainty created unprecedented conditions for all market players. The dominant players on the supply side of the market were able to adapt in a relatively short time, as their digital infrastructure benefited from previous thorough optimization. Market players long hesitant to decide on whether and when to start with the digital transformation were forced to improvise under the pressure of market survival. The demand side of the market also faced its challenges, in particular the management of its own time, which represented a largely complex element with the increasing interest in working from home. Early analyses [32-33] pointed to the paradox of maximizing e-commerce benefits for customers, who shifted the dominant part of their online activities to working days in order to make use of additional benefits. As the pandemic progressed, the panic of online customers stabilized, and the accumulation of online activities within the working morning spread smoothly throughout the working day. Weekends, on the other hand, became a time of digital relaxation. The massive drop in online interactions recorded during weekends compared to the pre-pandemic standard / captured in the reference research [15] / was largely taken by surprise by the operators of the supply side of the electronic market. They responded to this by a year-on-year decrease in online activity during weekends, while their online activity remained unchanged working days. In terms of regional specificity, the findings point to the fact that the similarity of government restrictive measures combined with the level of development of the online market generates relatively equal market responses to the evolution of e-consumer behavior patterns [40]. They also point to the fact that, in terms of the e-market development parameter, the digital market in the Czech Republic shows significant signs of above-average development. As for the trends in the development of e-consumer behavior itself, as the pandemic progressed, the steepness of the trends began to decrease. Based on the deepening of knowledge, as well as on the preliminary processing of the data from the second observation period, it could be assumed that a unique trend of behavior would grow, which would be a synthesis of the pre-pandemic and panic reactions from the times of the first wave of the pandemic. This assumption was confirmed by the data from the third observation period, based on which the delta of change necessary to complete the empirical model was identified.

At this point, the implications for science and practice were formulated. From the point of view of the deepening of knowledge in the field of e-commerce, it can be stated that the digital ecosystem is relatively resilient. Both sides of the market adapted relatively quickly to highly non-standard conditions, while the process of adaptation did not show 
significant shortcomings. The radical shift of the market from off-line to on-line environment provides space for science to generate new knowledge. In terms of practical implications, it should be noted that both the demand and supply side of the market actively used the circumstances to maximize the benefits. The supply side benefited from active feedback and based on online information, actively optimized the process towards efficiency. This can be seen in the year-on-year decline in online activities during weekend, compared to an almost $120 \%$ increase in efficiency in the number of interactions per post. The demand side benefited from shortening communication channels, where it actively sought additional benefits from consumption in the form of discounts or promotions. These were a kind of reward for participating in e-marketing communication of e-shops. Benefit maximization also occurred secondarily, where customers found the time needed for such participation in the morning, during working days. However, this trend has stabilized as the pandemic progresses, but certain elements of this trend will be reflected in the new norm that will occur in the post-pandemic period. In general, it can be stated that a proactive approach to digitization, both on the supply and demand side, is a new norm. The issue of finding effective tools for optimizing e-business is therefore a promising area for further research in economics and management sciences.

Despite the considerable efforts of the authors, it can be stated that the submitted study still has some limitations, which result predominantly from the nature of the data. Despite the large datasets, the data are predominantly of a qualitative nature. Another limitation is a certain degree of geographical specificity of the analyzed market. However, given the relatively high level of market development, the same results can be expected in markets with moderately to more developed online infrastructures.

Author Contributions: Conceptualization, F.P. and R.V; methodology, F.P.; software, R.V.; validation, R.V. and F.P.; formal analysis, F.P.; investigation, M.K.; resources, M.K. and F.P.; data curation, P.M.; writing - original draft preparation, F.P.; writing - review and editing, F.P. and R.V.; visualization, R.V.; supervision, P.M.; project administration, P.M.; funding acquisition, F.P. and P.M. All authors have read and agreed to the published version of the manuscript.

Funding: This research was funded by the Slovak Republic scientific grant agency VEGA, grant number 1/0140/21; This research was funded by the VŠB - Technical University of Ostrava, grant number SP2022/29.

Data Availability Statement: Does not apply.

Acknowledgments: Does not apply.

Conflicts of Interest: The authors declare no conflict of interest.

\section{References}

1. Wendy W.M.; Schweidel, D.A. Online Product Opinions: Incidence, Evaluation, and Evolution. Marketing Science 2011, 31(3), 372-386.

2. Bjørgen, A.; Bjerkan, K.Y; Hjelkrem. O.A. E-groceries: Sustainable last mile distribution in city planning. Research in Transportation Economics 2021, 87, 100805.

3. Nosratabadi, S.; Mosavi, A.; Shamshirband, S.; Kazimieras Zavadskas, E.; Rakotonirainy, A.; Chau, K.W. Sustainable Business Models: A Review. Sustainability 2019, 11, 1663.

4. Štefko, Róbert, Peter Dorcak, and František Pollák. Shopping on the internet from the point of view of customers. Polish Journal of Management Studies 2011, 4, 214-22.

5. Tisdell, C.A. Economic, social and political issues raised by the COVID-19 pandemic, Economic Analysis and Policy 2020, 68, 1728.

6. Habib, S.; Hamadneh, N.N. Impact of Perceived Risk on Consumers Technology Acceptance in Online Grocery Adoption amid COVID-19 Pandemic. Sustainability 2021, 13, 10221.

7. Villa, R.; Monzón, A. Mobility Restrictions and E-Commerce: Holistic Balance in Madrid Centre during COVID-19 Lockdown. Economies 2021, 9, 57.

8. IRozhlas. Available online: https://www.irozhlas.cz/ekonomika/eet-koronavirus-epidemie-konec-prodeje_2003231323_tzr (accessed on 23rd January 2021).

9. Kurzy.cz. Available online: https://www.kurzy.cz/zpravy/537359-blizi-se-krachy-cerpacich-stanic-ropa-je-v-korunachnejlevnejsi-od-roku-1999-zajem-ridicu-o/ (accessed on 22nd January 2021). 
10. Businessinfo.cz. Available online: https://www.businessinfo.cz/clanky/koronavirus-meni-podnikani-v-cesku-kdo-jsou-vitezove-a-porazeni-soucasne-krize/ (accessed on 22nd January 2021).

11. Valaskova, K.; Durana, P.; Adamko, P. Changes in Consumers' Purchase Patterns as a Consequence of the COVID-19 Pandemic. Mathematics 2021, 9, 1788.

12. Kirk, C.P.; Rifkin, L.S. I'll Trade You Diamonds for Toilet Paper: Consumer Reacting, Coping and Adapting Behaviors in the COVID-19 Pandemic. J. Bus. Res. 2020, 117, 124-131.

13. Balmford, B.; Annan, J.D.; Hargreaves, J.C. et al. Cross-Country Comparisons of Covid-19: Policy, Politics and the Price of Life. Environ Resource Econ 2020, 76, 525-551.

14. Kurzy.cz. Available online: https://www.kurzy.cz/zpravy/546339-accenture-pandemie-zmenila-spotrebitelske-chovani-lidi-meni-nakupni-priority-a-vice-dbaji-na/ (accessed on 3rd December 2021).

15. Pollák, F.; Dorčák, P. The Effective Use of Facebook by Small and Medium-Sized Enterprises Operating in Slovakia. Mark. Tržište 2016, 28, 79-91.

16. Euromoney Country Risk. Available online: https://www.euromoneycountryrisk.com/article/b1mfm2pd7wr7b5/ecr-survey-results-q2-2020-covid19-crisis-increases-the-economic-and-political-risks-for-us-japan-europe-and-ems (accessed on 22nd January 2021).

17. Iprosperita.cz. Available online: https://www.iprosperita.cz/lobby-info/10537-koronavirus-prinesl-nove-trendy-v-chovani-spotrebitelu (accessed on 3rd December 2021).

18. Trabucco, M.; De Giovanni, P. Achieving Resilience and Business Sustainability during COVID-19: The Role of Lean Supply Chain Practices and Digitalization. Sustainability 2021, 13, 12369.

19. Chen, J.; Wang, H.; Zhong, R.Y. A supply chain disruption recovery strategy considering product change under COVID-19. J Manuf Syst. 2021, 60, 920-927.

20. Krchova, H.; Svejnova Hoesova, K. The Impact of Modern Communication Marketing Tools to Increase the Innovativeness of Business. Marketing and Management of Innovations 2021, 3, 117-126.

21. Zimbron, D.A.M. Modification of the consuption habits of generation Z, caused by COVID-19. Caderno Profissional De Marketing Unimep 2020, 8(4), 118-141.

22. Moon, J.; Choe, Y.; Song, H. Determinants of Consumers' Online/Offline Shopping Behaviours during the COVID-19 Pandemic. Int. J. Environ. Res. Public Health 2021, 18, 1593.

23. Al-Hattami. H.M.; Corona, C.G. Determinants of intention to continue usage of online shopping under a pandemic: COVID-19, Cogent Business \& Management 2021, 8(1), 1936368.

24. Jensen, K.; Yenerall, J.; Chen, X.; Yu, T. US Consumers' Online Shopping Behaviors and Intentions During and After the COVID19 Pandemic. Journal of Agricultural and Applied Economics 2021, 53(3), 416-434.

25. Awada, M.; Gale, L.; Becerik-Gerber, B.; Shawn, R. Working from home during the COVID-19 pandemic: Impact on office worker productivity and work experience. Work 2021, 69(4), 1171-1189.

26. Habel, J.; Alavi, S.; Linsenmayer, K. From personal to online selling: How relational selling shapes salespeople's promotion of e-commerce channels. Journal of Business Research 2021, 132, 373-382.

27. Nemțeanu, M.S.; Dabija, D.C. Best practices of nongovernmental organisations in combatting COVID-19. In Proceedings of the 6th BASIQ International Conference on New Trends in Sustainable Business and Consumption, Messina, Italy, 4-6 June 2020; Pamfilie, R., Dinu, V., Tăchiciu, L., Pleșea, D., Vasiliu, C., Eds.; ASE: Bucharest, Romanian, 2020; pp. 626-633.

28. S. Lakshmi. Revenge Buying. Biosc.Biotech.Res.Comm 2020. 13(15), 204-206.

29. Muangmee, C.; Kot, S.; Meekaewkunchorn, N.; Kassakorn, N.; Khalid, B. Factors Determining the Behavioral Intention of Using Food Delivery Apps during COVID-19 Pandemics. J. Theor. Appl. Electron. Commer. Res. 2021, 16, 1297-1310.

30. Dabija, D.-C.; Bejan, B.M.; Pușcaș, C. A Qualitative Approach to the Sustainable Orientation of Generation Z in Retail: The Case of Romania. J. Risk Financial Manag. 2020, 13, 152.

31. Zboží a prodej. Available online: https://www.zboziaprodej.cz/2021/02/01/spotrebitelske-chovani-letos-ovlivni-deset-hlavnitrendu/ (accessed on 3rd December 2021).

32. Pollák, F.; Vavrek, R.; Váchal, J.; Markovič, P.; Konečný, M. Analysis of Digital Customer Communities in Terms of Their Interactions during the First Wave of the COVID-19 Pandemic. Manag. Marketing. Chall. Knowl. Soc. 2021, 16, $134-151$.

33. Pollak F.; Markovic P.; Vachal J.; Vavrek R. Analysis of E-Consumer Behavior During the COVID-19 Pandemic. In: Gao H., Kim J.Y., Hussain W., Iqbal M., Duan Y. (eds) Intelligent Processing Practices and Tools for E-Commerce Data, Information, and Knowledge. EAI/Springer Innovations in Communication and Computing. Springer, Cham. 2022, 95-114.

34. Greenhow, C.; Chapman, A. Social distancing meet social media: digital tools for connecting students, teachers, and citizens in an emergency. Information and Learning Sciences 2020, 121(5/6), 341-352.

35. Cato, S.; Iida, T.; Ishida, K.; Ito, A.; Katsumata, H.; Mori, K.M.; Shoji, M. Social media infodemics and social distancing under the COVID-19 pandemic: public good provisions under uncertainty, Global Health Action 2021, 14(1), 1995958.

36. Bond, B.J. Social and parasocial relationships during COVID-19 social distancing. Journal of Social and Personal Relationships 2021, 38(8), 2308-2329.

37. Shipps, B.; Phillips, B. Social Networks, Interactivity and Satisfaction: Assessing Socio-Technical Behavioral Factors as an Extension to Technology Acceptance. J. Theor. Appl. Electron. Commer. Res. 2013, 8, 35-52.

38. Hansen, S.S.; Lee, J.K. What Drives Consumers to Pass Along Marketer-Generated eWOM in Social Network Games? Social and Game Factors in Play. J. Theor. Appl. Electron. Commer. Res. 2013, 8, 53-68.

39. Dobrovič, J.; Čabinová, V.; Gallo, P.; Partlová, P.; Váchal, J.; Balogová, B.; Orgonáš, J. Application of the DEA Model in Tourism SMEs: An Empirical Study from Slovakia in the Context of Business Sustainability. Sustainability 2021, $13,7422$. 
40. Pollák, F.; Konečný, M.; Ščeulovs, D. Innovations in the Management of E-Commerce: Analysis of Customer Interactions during the COVID-19 Pandemic. Sustainability 2021, 13, 7986.

41. Ecommerce Bridge. Available online: https://www.ecommercebridge.sk/najvacsie-e-shopy/ (accessed on 20 March 2020). 